\title{
Acesso à educação infantil no novo PNE: parâmetros de planejamento, efetivação e exigibilidade do direito ${ }^{1}$
}

Salomão Ximenes*

Ananda Grinkraut**

*Doutor em Direito do Estado (USP) e coordenador do programa Ação na Justiça da Ação Educativa

E-mail: salomao.ximenes@acaoeducativa.org

**Doutoranda em Educação (USP) e assessora do programa Diversidade, Raça e Participação da Ação Educativa

E-mail: ananda.grinkraut@acaoeducativa.org
Resumo: Este artigo tem como objetivo analisar o conteúdo da Meta 1 do atual Plano Nacional de Educação (PNE), sobretudo no que se refere à efetivação do direito de acesso à educação infantil de qualidade. Inicia-se diferenciando as metas objetivas de atendimento e o direito à educação infantil enquanto prerrogativa constitucional exigível, buscando evidenciar o lugar do PNE no sistema normativo brasileiro. Em seguida, contextualizamos o texto da Meta 1 em seus aspectos político e jurídico, sendo também abordadas as estratégias que a compõem. Destacamos a necessidade de estabelecer indicadores e parâmetros transparentes e socialmente válidos para o cálculo da meta. Por fim, são apresentados desafios para sua efetivação, bem como a expectativa de que a meta mínima de $50 \%$ inscrita no texto da Lei seja suplantada pela realidade da pressão popular associada ao direito de estatura constitucional.

Palavras-chave: Educação infantil. Plano Nacional de Educação. Acesso à educação. Direito à educação. Políticas públicas.

Este artigo é fruto de estudos e intervenções desenvolvidos pelos autores junto aos programas Ação na Justiça e Diversidade, Raça e Participação, da Ação Educativa. 
INTRODUÇÃO

A aprovação do novo Plano Nacional de Educação (PNE), publicado através da Lei $n$ ํ 13.005/2014, traz um conjunto de desafios para as políticas públicas voltadas à efetivação do direito à educação infantil, assim como para a interpretação dos deveres jurídicos que devem ser assumidos pelo poder público, principalmente pelos municípios, com a necessária colaboração da União e dos estados.

O PNE, longe de significar o esgotamento de um ciclo de regulamentação do direito à educação, abre uma nova etapa de proteção jurídica e de planejamento público para sua efetivação, na qual está prevista a edição de novas normas, além da revisão e adequação de políticas em curso, tendo como instrumento principal, no âmbito local, os planos de educação dos municípios e estados.

Neste artigo buscamos analisar a contribuição da Meta 1 do novo PNE ao tratar dessas questões no cenário atual. Como veremos, ainda que a Meta 1 , no tocante ao atendimento das crianças de 0 a 3 anos, tenha frustrado a expectativa de boa parte das organizações, pesquisadores e militantes educacionais - expressa principalmente na Conferência Nacional de Educação (BRASIL; CONAE, 2010) - ao basicamente repetir o percentual mínimo de atendimento inscrito no PNE anterior, tanto o contexto de exigibilidade em que se insere o novo Plano como as metas relacionadas à formação, à valorização docente e ao financiamento público da educação, bem como o conjunto de estratégias presente em tais metas, podem significar novo alento para a agenda de generalização do acesso à creche no Brasil ${ }^{2}$.

Contextualizaremos o texto da Meta 1, em seus aspectos político e jurídico. Em seguida, trataremos da necessidade de estabelecer nacionalmente parâmetros transparentes e socialmente válidos para o cálculo dos indicadores de frequência à creche, já que nossa experiência nesse campo vem demonstrando que, a depender do critério adotado por cada ente federado, pode-se estar mais próximo ou mais distante das metas quantitativas de atendimento. Com implicações ainda mais amplas se coloca a necessária diferenciação entre indicadores e metas objetivas de atendimento e o direito à educação infantil enquanto prerrogativa constitucional exigível. Reduzir este àquele

A educação básica não obrigatória é regida pelo princípio da generalização, que determina que o acesso ao direito deve estar disponível a todos que venham a demandálo. Difere a generalização do princípio da universalização, que objetiva atender todas as crianças e adolescentes em determinada faixa etária de escolarização obrigatória (XIMENES, 2014). 
significaria retroceder dez anos em sua afirmação jurídica, quando se podia negar o exercício desse direito constitucional sob o argumento de se tratar de norma "programática"; por outro lado, reduzir o direito à educação infantil à sua dimensão de exigibilidade individual, ainda que esta seja essencial, significaria desconsiderar que seu exercício é necessariamente coletivo e que as exigências de qualidade requerem expansão planejada e elevação progressiva de investimentos em novas instituições públicas, equipamentos, material didático-pedagógico, formação e incorporação de novos professores.

A esse tema, que trataremos já no início do artigo com o objetivo de dissipar compreensões de senso comum sobre o conteúdo do direito e o lugar do PNE no sistema normativo, está relacionado o papel central que as estratégias do Plano dedicam à questão da demanda. Nada menos que cinco das 17 estratégias presentes na Meta 1 regulam obrigações relativas a esse aspecto, seja o levantamento periódico e publicação da demanda geral manifesta, a identificação e mobilização de grupos demandatários específicos, como beneficiários de programas sociais, ou ainda a chamada "busca ativa" de crianças que por razões de pobreza, abandono ou outras dificuldades não tenham manifestado intenção de frequência à creche e à pré-escola.

Ao final dessa análise, ficamos com a forte convicção que, se respeitados os direitos de acesso e se, como consequência, implantar os mecanismos de registro de demanda e de mobilização social para o acesso à creche, a meta mínima de 50\% inscrita no texto da Lei deverá ser suplantada pela realidade da pressão popular associada ao direito de estatura constitucional. Por sorte, não há contradição interna entre os dispositivos do PNE, já que a Meta 1 é expressamente um parâmetro mínimo nacional. Será a demanda manifesta em cada município que definirá, no fim das contas, o quanto essa meta se aproximará do somatório do direito de cada criança detentora da prerrogativa de acesso à educação infantil em creche de qualidade no país.

\footnotetext{
A ideia de norma programática, do ponto de vista técnico-jurídico, busca descrever normas jurídicas que não produziriam efeitos diretos, mas que dependeriam de regulamentação ou do cumprimento de determinados programas de implementação. Em geral, essa categoria foi utilizada para negar a possibilidade de se exigir diretamente da Constituição os direitos sociais nela estipulados, como é o caso do direito à educação infantil em creches e pré-escolas (CF/88, art. 208, IV). A partir de 2005 essa posição foi superada por meio da jurisprudência do STF justamente sobre o direito à educação infantil.
} 
ANTERIORIDADE E SUPERIORIDADE NORMATIVA DO DIREITO À EDUCAÇÃO INFANTIL EM SUAS DIMENSÕES SUBJETIVA E OBJETIVA: O PNE EM SEU DEVIDO LUGAR

O novo PNE, tanto por seu conteúdo como em razão da agenda de regulamentações que propõe, atualiza questões sobre a exigibilidade do direito, tema que vem ganhando enorme impulso nos últimos anos com a crescente participação do Sistema de Justiça (Judiciário, Ministério Público, Defensoria Pública e associações civis) na pressão por promoção do acesso à educação infantil. No espaço deste artigo não nos cabe entrar em discussões sobre a oportunidade e adequação do tratamento dessas políticas públicas pelo Judiciário ${ }^{4}$, mas apenas alertar aos intérpretes do PNE sobre alguns requisitos básicos para a sua contextualização.

O novo PNE não é uma ilha no universo normativo. Há todo um arcabouço constitucional, legal e jurisprudencial que o antecede e coloca-se hierarquicamente acima de seu conteúdo. Ou seja, todas as disposições do PNE, principalmente suas metas e estratégias, precisam ser interpretadas conforme a Constituição.

Hoje, em contexto muito diferente daquele encontrado pelo PNE anterior (Lei no 10.172, de 2001), felizmente não mais se discute se a educação infantil é direito exigível, ou seja, justiciável. Isso porque, em relação especificamente ao direito de exigir acesso à educação infantil, as mobilizações da sociedade civil junto ao Sistema de Justiça tiveram papel decisivo na consolidação, a partir de 2005, de uma interpretação constitucional favorável no Supremo Tribunal Federal (STF). Segundo essa posição, que se consolidou em todo o país, do ponto de vista técnico a educação infantil é equivalente a um direito público subjetivo ${ }^{5}$, já que não pode continuar sendo tratada como mera norma "programática". O STF, nesse sentido, vem afirmando o direito à educação infantil como prerrogativa constitucional indisponível deferida às crianças, sendo que esse direito não depende de regulamentações para ser exigível, já que seu conteúdo básico pode ser extraído diretamente do texto da Constituição ${ }^{6}$.

4 Sobre esse tema, destacando uma nova abordagem para o controle jurisdicional das políticas públicas de educação infantil a partir do contexto do município de São Paulo, recomendamos: RIZZI; XIMENES, 2014.

5 “[...] todas as outras situações jurídico-constitucionais [além do ensino obrigatório] que sejam redutíveis ao esquema direito individual - dever do Estado configuram, na mesma sorte, direitos públicos subjetivos" (BARROSO, 2003, p. 115).

6 Síntese com base no Acórdão do RE-AgR 410715/SP, Segunda Turma, Relator Min. Celso de Mello, julgado em 22/11/2005. 
Essa posição da jurisprudência destaca uma diferenciação básica presente na teoria dos direitos fundamentais. Estes se apresentam em duas dimensões: subjetiva e objetiva. Na dimensão subjetiva pública, o direito à educação dá ao indivíduo e aos seus representantes a faculdade de exigir do Estado o cumprimento de um dever jurídico que venha a favorecê-lo direta ou indiretamente. Já a dimensão objetiva pública não diz respeito a um indivíduo ou sujeito específico, mas as deveres objetivamente atribuídos ao Estado. Essa dimensão objetiva assume duas formas básicas: i) obrigações normativas direcionadas ao legislador (em sentido amplo), que estabelecem a obrigatoriedade de atuação para a criação do marco legal, institucional e das condições materiais para o exercício desses direitos; e ii) fornecimento prático das prestações sociais aos sujeitos de direito, como meio para a realização dos direitos subjetivos e execução das imposições legais e institucionais. A dimensão objetiva se caracteriza, assim, por vincular o sujeito - no caso o Estado - por meio da "[...] fundamentação de deveres que não estão em relação com qualquer titular concreto” (CANOTILHO, 1999, p. 1122).

Esse recurso à teoria do direito é necessário para evidenciar que o PNE, que regulamenta o artigo 214 da Constituição, é a expressão máxima da dimensão objetiva do direito à educação no Brasil, já que visa planejar e estruturar tanto as obrigações normativas (por exemplo, as obrigações de regulamentação dos planos locais de educação) como o ritmo e o alcance do fornecimento das prestações estatais aos sujeitos (por exemplo, a meta de atendimento mínimo de $50 \%$ da população com idade até 3 anos).

O planejamento jurídico da política educacional, no entanto, não esvazia a força da dimensão subjetiva do direito à educação. Ou seja, não adia para 2024 a possibilidade de se exigir o direito de acesso a creches de qualidade, em ações individuais ou coletivas. Interpretar o PNE dessa forma seria, além de errado do ponto de vista técnico-jurídico, contrário à Constituição, que em seu art. 208, IV, é taxativa quanto ao dever do Estado à garantia desse direito.

Esse não é um debate meramente teórico, já que, ainda com o PNE em tramitação no Congresso Nacional começaram a surgir questionamentos quanto ao direito subjetivo de acesso e à possibilidade de exigir judicialmente sua realização. Em caso julgado pelo STF em 2014, por exemplo, o município de Guarujá (SP) argumentou que o processo de ampliação de vagas em creches havia sido regulamentado no Plano Municipal de Educação e que, portanto, as decisões judiciais que concediam vagas estariam em confronto 
com esse Plano. Sem entrar no mérito do Plano Municipal, é elucidativo o parecer do Procurador-Geral da República, que distingue as dimensões do direito já apresentadas:

[...] a circunstância de a ampliação do número de vagas nas creches municipais estar regulamentada pela legislação infraconstitucional - Lei Municipal 3.984/2012, que institui o Plano Municipal de Educação para o exercício de 2013 - não exime o Município de conferir condições reais e efetivas para o usufruto do direito constitucional de acesso à educação infantil. O princípio da legalidade, indicado pelo requerente, implica obediência não apenas à legislação infraconstitucional, mas, também e precipuamente, à Constituição (BRASIL, 2014).

Ou seja, ainda que se venha a demonstrar o cumprimento das metas objetivas estabelecidas no planejamento educacional, isso representará o atendimento de apenas uma das duas dimensões jurídicas essenciais, que é o dever objetivo do Estado de adotar medidas para a realização do direito à educação conforme estabelecido nos planos de educação. 0 não cumprimento desse dever pode, em si, gerar responsabilização e cobrança por meio do Sistema de Justiça. Cumprindo-se ou não as metas relativas à educação infantil, entretanto, persistirá a dimensão subjetiva, já que esta se relaciona aos direitos inalienáveis de cada criança. Comprovada a exclusão escolar, há o direito individual e coletivo de exigir sua superação.

O levantamento e a publicização periódica da demanda manifesta, como veremos, é o mecanismo que o novo PNE coloca à disposição para aproximar as dimensões objetiva e subjetiva do direito à educação infantil em creches. Ao determinar que, em complemento à meta mínima objetivamente estipulada, o poder público institua mecanismos de escuta da demanda popular, a Lei busca adequar a resposta estatal à dimensão real dos direitos subjetivos em questão. Identificada a demanda, antes e durante a formulação ou atualização dos planos locais ou ainda em seu processo de implementação, será possível estabelecer deveres objetivos condizentes com a dimensão real de exclusão em cada contexto. Ao atender tal demanda no planejamento público, por sua vez, poderemos inclusive reduzir o recurso ao Sistema de Justiça.

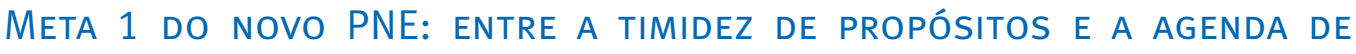
DEMOCRATIZAÇÃO DO ACESSO

A primeira meta do novo PNE trata especificamente do direito à educação infantil. Antes de se considerar o conteúdo das estratégias previstas para 0 seu alcance, vale registrar que, no que se refere à população com idade até 3 
anos, essa meta acabou por repetir quase que integralmente o texto do PNE 2001-2011, como se pode verificar no quadro a seguir:

\section{\begin{tabular}{l|l} 
PNE 2001-2011 & PNE 2014-2014
\end{tabular}}

Objetivos e Metas [...] 1.3.1. Ampliar a oferta de educação infantil de forma a atender, em cinco anos, a $30 \%$ da população de até 3 anos de idade e $60 \%$ da população de 4 e 6 anos (ou 4 e 5 anos) e, até o final da década, alcançar a meta de $50 \%$ das crianças de 0 a 3 anos e $80 \%$ das de 4 e 5 anos.

Meta 1: universalizar, até 2016, a educação infantil na pré-escola para as crianças de 4 (quatro) a 5 (cinco) anos de idade e ampliar a oferta de educação infantil em creches de forma a atender, no mínimo, 50\% (cinquenta por cento) das crianças de até 3 (três) anos até o final da vigência deste PNE.

Quadro 1 - Redação da meta de atendimento na educação infantil, Brasil, PNE 2001-2011 e PNE 2014-2024.

Fonte: Lei 10.172/2001 e Lei 13.005/2014.

A principal diferença refere-se ao atendimento da população de 4 e $5^{7}$ anos. Enquanto o PNE anterior projetava alcançar $80 \%$ de atendimento nessa faixa etária, o novo PNE se propõe a universalizá-lo até 2016, de forma a atender o previsto na Emenda Constitucional 59/2009, que ampliou a faixa de obrigatoriedade do ensino para a população com idade entre 4 e 17 anos, a ser implementada progressivamente até aquele ano. Nesse sentido, a meta não inova, apenas reafirma o que já havia sido estabelecido na Constituição. Como veremos, nesse ponto a inovação do PNE aparece nas estratégias a serem adotadas para alcançar a universalização pretendida.

Com relação à meta final de atendimento das crianças até 3 anos de idade, agora a ser alcançada até 2024, manteve-se o mesmo texto do PNE 2001-2011. Com isso, prorrogou-se esse objetivo por mais 13 anos. Duas alterações de redação também merecem ser notadas. Primeiro, o novo texto não apresenta uma meta intermediária para esse atendimento; segundo, há a explicitação de se tratar os $50 \%$ de objetivo mínimo, ou seja, não como meta fixamente estabelecida. Isso, como veremos, abre espaço para que na implementação

Até 2005 a educação infantil atendia crianças de 0 a 6 anos de idade. Em 2005, a Lei 11.114/2005 alterou a LDB e tornou obrigatória a matrícula das crianças de 6 anos no ensino fundamental. A educação infantil passou a atender a partir de então crianças entre 0 e 5 anos. 
das estratégias e na disseminação dos planos locais de educação se possa almejar a realização de objetivos superiores, adequados às realidades específicas e, principalmente, à demanda popular por esse direito.

O texto da Meta 1 foi considerado excessivamente tímido por várias organizações da sociedade civil e do próprio movimento da educação infantil. Ao final de sua apreciação por deputados e senadores, a Meta 1 praticamente não sofreu alteração em relação ao Projeto de Lei encaminhado pelo Executivo (PL 8.035/2010), o que significa que não repercutiu nessa meta a elevação dos investimentos em educação em relação ao PIB de $7 \%$ para $10 \%$, conquistada no Congresso. No entanto, essa não foi a posição pactuada e aprovada pela sociedade brasileira em relação à expansão da educação infantil, como pode ser observado no documento final da Conferência Nacional de Educação (BRASIL; CONAE, 2010), que deveria ter servido de base para a elaboração do referido PL. O distanciamento entre o aprovado na Conae e a proposta do governo federal, por sua vez, provocou uma enxurrada de emendas durante a tramitação do PNE no Congresso Nacional ${ }^{8}$.

O documento final da Conae 2010, ao abordar questões relativas à democratização do acesso à educação infantil, destaca:

A garantia de aporte financeiro do Governo Federal para a construção, reforma, ampliação de escolas e custeio com pessoal, para aumento da oferta de vagas em 50\%, até 2010, e a universalização do atendimento à demanda manifesta, até 2016, especificamente às crianças da faixa etária de 0 a 3 anos de idade, em período integral, a critério das famílias, assegurando progressivamente seu atendimento por profissionais com nível superior e garantia de formação continuada (BRASIL, 2010, p. 68).

Com relação às emendas, cita-se a que foi formulada pela Campanha Nacional pelo Direito à Educação ${ }^{9}$ e que foi apresentada formalmente por dezenas de deputados. Basicamente, o texto reitera o que havia sido aprovado na Conae, com adaptações relativas aos prazos de realização, isto é:

Meta 1: Até 2016, universalizar o atendimento escolar da população de 4 e 5 anos e ampliar a oferta educacional de forma a atender em creches no mínimo 50\% da população de até 3 anos, e, até o último ano de vigência desta Lei, universalizar o atendimento da demanda manifesta por creche.

8 O conjunto de emendas apresentadas ao PL 8.035/2010 pode ser acessado no banco de emendas sistematizado pelo Movimento PNE pra Valer e Undime. Disponível em: «http:// pne.undime.org.br/s.

9 A Campanha Nacional pelo Direito à Educação, criada em 1999, constitui-se como uma rede que articula mais de 200 grupos e entidades distribuídos por todo o país. Participou intensamente dos processos participativos de elaboração do PNE, lançando inclusive o movimento "PNE pra Valer!". 
Tanto o texto aprovado na Conae, em 2010, como a emenda apresentada pela Campanha tinham como propósito superar o paradigma inscrito no PNE 20012011, não cumprido, como se sabe, baseado no estabelecimento de uma meta de atendimento sem referência ao planejamento do atendimento da demanda manifesta. Nesse contexto, entendiam inadmissível prorrogar por mais de uma década uma meta que, em si, não dá conta da dívida histórica quanto à oferta da educação infantil. Propuseram, assim, a ampliação do objetivo legal de atendimento de 0 a 3 anos e o reconhecimento do conceito de demanda manifesta para essa faixa etária, deixando os $50 \%$ de atendimento como meta intermediária. Ou seja, estabelecia assim uma solução de transição entre o regime com base na meta de atendimento e o regime baseado no atendimento de toda a demanda objetivamente aferida. No entanto, apesar do intenso debate e da legitimidade do texto aprovado na Conae 2010, prevaleceu a versão do governo.

Apesar da timidez de propósitos da Meta 1 em relação às crianças de 0 a 3 anos, suas estratégias apontam a possibilidade de se avançar na ampliação da garantia desse direito, bem como nas condições de permanência e de qualidade da oferta. Tal afirmação sustenta-se no conteúdo de várias das 17 estratégias estabelecidas nessa meta, as quais, se implementadas, poderão no fim das contas garantir o atendimento de toda a demanda manifesta, superando-se o patamar mínimo de $50 \%$ da população na referida faixa etária. Destacam-se nesse sentido as estratégias relacionadas ao acesso, à expansão das redes públicas, ao levantamento de demanda e à busca ativa.

Sobre o acesso e a expansão das redes públicas, além da previsão de definição, em regime de colaboração entre os entes federados, de metas de expansão segundo padrão nacional de qualidade (1.1), previu-se também a ampliação de programa nacional de construção e reestruturação de unidades públicas de educação infantil (1.5), ainda que, em ambos os casos, sem parâmetros objetivos a serem alcançados em termos de participação do setor público na oferta educacional. Previu-se ainda o fomento do atendimento da população do campo e das comunidades indígenas e quilombolas, nas respectivas comunidades (1.10), e foi destacada a prioridade de acesso à educação infantil às crianças com deficiência, transtornos globais do desenvolvimento e altas habilidades ou superdotação, fomentando-lhes a oferta do atendimento educacional especializado complementar e suplementar (1.11). No caso das crianças de famílias beneficiárias de programas de transferência de renda, previu-se o fortalecimento do acompanhamento e monitoramento do acesso e permanência nessa etapa da educação (1.14). 
Evidencia-se também proposta inovadora em termos de metas de equalização, também formulada pelas organizações que compõem a Campanha Nacional pelo Direito à Educação. Vejamos:

\begin{abstract}
1.2) garantir que, ao final da vigência deste PNE, seja inferior a 10\% (dez por cento) a diferença entre as taxas de frequência à educação infantil das crianças de até 3 (três) anos oriundas do quinto de renda familiar per capita mais elevado e as do quinto de renda familiar per capita mais baixo (CAMPANHA NACIONAL PELO DIREITO À EDUCAÇÃO, 2010);
\end{abstract}

Considerando que atualmente essa diferença de oportunidades de acesso é absurda, ou seja, que o exercício do direito à educação infantil não obrigatória no Brasil é fortemente marcado por uma discriminação em função da renda das famílias, essa estratégia de equalização, quando realizada, terá impacto direto no alcance da própria meta. Enquanto apenas 15,9\% das crianças de 0 a 3 anos estavam matriculadas em 2012, essa frequência chegava a 44,5\% entre o quintil mais rico, significando uma diferença de $28,6 \%$ (BRASIL; IBGE/ PNAD, 2012). Ampliar o atendimento das crianças de até 3 anos e ao mesmo tempo reduzir significativamente essa diferença nas taxas de frequência entre a população mais rica e a população mais pobre, sem retroceder em nenhuma das faixas, exigirá um esforço significativo de equalização por meio da ação do Estado. Acompanhar a evolução desse indicador, em nível nacional e em cada ente federado, será essencial nas avaliações periódicas de implementação do atual PNE.

Além da preocupação específica com o acesso e a permanência por parte dos beneficiários de programas de transferência de renda, há quatro estratégias voltadas ao levantamento de demanda e à busca ativa, vejamos:

1.3) realizar, periodicamente, em regime de colaboração, levantamento da demanda por creche para a população de até 3 (três) anos, como forma de planejar a oferta e verificar o atendimento da demanda manifesta;

1.4) estabelecer, no primeiro ano de vigência do PNE, normas, procedimentos e prazos para definição de mecanismos de consulta pública da demanda das famílias por creches; [...]

1.15) promover a busca ativa de crianças em idade correspondente à educação infantil, em parceria com órgãos públicos de assistência social, saúde e proteção à infância, preservando o direito de opção da família em relação às crianças de até 3 (três) anos;

1.16) o Distrito Federal e os Municípios, com a colaboração da União e dos Estados, realizarão e publicarão, a cada ano, levantamento da demanda manifesta por educação infantil em creches e pré-escolas, como forma de planejar e verificar o atendimento [grifos nossos].

O novo PNE, como se vê, estipula um detalhado regime de levantamento periódico da demanda porcreches e pré-escolas, articulando-oao planejamento público e à busca ativa. Foi previsto o estabelecimento, já no primeiro ano de vigência do Plano, de normas, procedimentos e prazos para o levantamento regular da demanda das famílias por creches. Tal regulamentação, em termos 
gerais, pode se dar em âmbito nacional, o que não exime os municípios da obrigação de estabelecerem normas próprias sobre o assunto.

As estratégias 1.3 e 1.16 coincidem em muitos pontos, ao estabelecerem parâmetros para a regulamentação e aplicação das obrigações de levantar e de publicar a demanda manifesta. Esta última estabelece que tal levantamento e publicação deve acontecer a cada ano e deve abranger toda a educação infantil, ainda que o conceito de demanda manifesta se adeque às etapas de escolaridade não obrigatórias. Os propósitos legais são analisar a efetividade das políticas de promoção do acesso e possibilitar a atualização do planejamento nesse campo. Previu-se também a promoção da busca ativa de crianças em idade correspondente à educação infantil, tendo como propósitos: a) instrumentalizar as políticas de universalização da préescola, possibilitando que sejam alcançadas aquelas crianças em situação de vulnerabilidade e exclusão, e b) enfrentar as desigualdades socioeconômicas no acesso à creche, por meio do estímulo à matrícula e frequência por parte das crianças dos estratos mais pobres. Nesse sentido, essa é uma estratégia complementar à meta de equalização já analisada (Estratégia 1.2).

Esses mecanismos de levantamento, estímulo e publicização da demanda tornam o processo de matrícula e as listas de espera, quando houver, mais transparentes e plausíveis de controle social, evitando a reprodução de práticas clientelistas e antidemocráticas nas políticas públicas de educação infantil. Também são essenciais para possibilitar um planejamento mais próximo da realidade, das demandas e necessidades da população local. A busca ativa de crianças na idade correspondente à educação infantil, mas que ainda não estão matriculadas, contribuirá para uma efetiva universalização do atendimento das crianças de 4 e 5 anos, e para o acesso das crianças pequenas que as famílias assim o desejarem. Vale mencionar que embora 0 acesso à pré-escola tenha crescido significativamente na última década, em 2012 era de $17,8 \%$ a taxa de exclusão de crianças de 4 e 5 anos, sendo que alcançava $22,4 \%$ entre os pobres, contra $5,4 \%$ no $1 / 4$ mais rico da população (BRASIL; IBGE/PNAD, 2012).

As estratégias da Meta 1 , se cumpridas, devem portanto proporcionar a ampliação do atendimento, a redução das disparidades e aprimorar as condições de oferta da educação infantil no país. São, nesse sentido, mais significativas que a própria meta em si, lembrando que esta deve ser entendida como objetivo mínimo, ou seja, não como meta fixamente estabelecida. Ao se identificar e planejar o atendimento à demanda manifesta, ao se realizar a 
busca ativa das crianças na idade correspondente, ao se prever a redução das disparidades no acesso, ao se fomentar o atendimento, garantindo-se as especificidades e necessidades da população do campo, comunidades indígenas e quilombolas, e ao se priorizar o atendimento de crianças com deficiência, transtornos globais do desenvolvimento e altas habilidades ou superdotação, a realidade seguramente exigirá o desenho de políticas públicas que venham a ultrapassar, ao final da década, o tímido objetivo mínimo de $50 \%$ de atendimento previsto na meta em questão.

No desenho dos planos estaduais e municipais de educação é esperado que a busca ativa, e o levantamento e publicação da demanda manifesta, venham a exigir o estabelecimento de objetivos superiores, o que é plenamente compatível com a Lei no 13.005/2014, já que esta estabelece objetivo mínimo.

Vale lembrar que essas estratégias buscam viabilizar o direito à educação infantil, direito já previsto na Constituição. Essa é uma prerrogativa subjetiva indisponível que não se esgota na projeção de realização da meta e de seu objetivo mínimo, ou seja, o PNE deve ser lido, compreendido e implementado em diálogo e consonância com as demais normas do sistema jurídico brasileiro. Sendo então a educação infantil (e o atendimento das crianças menores de 3 anos) um direito da criança e da família e um dever do Estado, deve-se garantir o atendimento de toda a demanda manifesta das crianças por todos os estados e municípios brasileiros, com a colaboração da União, independentemente de se ultrapassar a meta de $50 \%$ de frequência ao final da vigência do atual PNE.

Contudo, ainda que as estratégias tenham um potencial significativo para promover a ampliação da garantia do direito à educação, é fundamental discutir os indicadores e instrumentos para mensurar essa ampliação, o que será feito na próxima seção do artigo. 
SOBRE A NECESSÁRIA TRANSPARÊNCIA NO CÁLCULO DOS INDICADORES DE FREQUÊNCIA

Ainda que a formulação das metas e estratégias de um Plano de Educação constituam-se como um importante passo para que se avance na garantia do direito à educação, para que se tornem realidade, o monitoramento e a realização de avaliações sistemáticas do Plano são condições fundamentais. No caso da meta de acesso à educação infantil, na forma como está escrita e tomando em conta as fontes de dados hoje disponíveis, essa questão se torna ainda mais decisiva.

Apesar do estabelecimento de metas de expansão a partir da taxa de frequência das crianças de 0 a 5 anos de idade, ao que parece, até o momento, não há consenso em torno da metodologia de cálculo dessa taxa. Com base em diferentes metodologias e fontes de dados, é possível obter variações consideráveis nas taxas encontradas, com implicações no planejamento e na avaliação da política educacional. Isso, em especial, quando se trata do atendimento das crianças de 0 a 3 anos, já que até 2016, conforme previsto na nova redação da Constituição e replicado no PNE, deve-se universalizar 0 atendimento escolar das crianças e adolescentes com mais de 4 anos de idade.

A meta de expansão do PNE tem na taxa de frequência seu indicador de resultado e monitoramento, bem como seu indicador de equalização, neste caso, inscrito na Estratégia 1.2. Essa taxa expressa o percentual de atendimento por faixa etária e/ou por etapa e nível da educação e, por consequência, o percentual da população que ainda não frequenta o sistema educacional. No caso da educação infantil, as metas estabelecidas no PNE 2001-2011 e no PNE recém-aprovado podem ser observadas na tabela a seguir:

Tabela 1 - Metas estabelecidas para o atendimento das crianças de o a 5 anos, PNE 2001-2011 e PNE 2014-2024

\begin{tabular}{|l|l|l|l|l|}
\hline & \multicolumn{2}{|l|}{ PNE 2001-2011 } & \multicolumn{2}{l|}{ PNE 2014-2024 } \\
\hline Faixa etária & Em 2006 & Em 2011 & Em 2019 & Em 2024 \\
\hline 0 a 3 anos & $30 \%$ & $50 \%$ & - & $50 \%$ \\
\hline 4 e 5 anos & $60 \%$ & $80 \%$ & $100 \%$ & $100 \%$ \\
\hline
\end{tabular}

Fonte: Lei 10.172/2001 e Lei 13.005/2014.

Apresentam-se a seguir três tipos de taxa de frequência e as fontes de dados para obter tal informação, de forma a elucidar diferenças nos dados 
encontrados e a possibilitar reflexões acerca de possíveis implicações da utilização de cada uma dessas taxas na formulação dos Planos de Educação, e, principalmente, avaliação e monitoramento de suas metas.

No âmbito da política educacional tem-se utilizado, basicamente, a taxa bruta de escolarização, a taxa de frequência bruta e a taxa de frequência líquida. A taxa bruta de escolarização é a proporção entre o total de matrículas em determinado nível de ensino em relação à população na faixa etária adequada a esse nível de ensino (IBGE, 2014). Já a taxa de frequência bruta referese à proporção da população em determinada faixa etária que frequenta o sistema educacional, não importando o nível ou a modalidade de ensino em que está matriculada, e a taxa de frequência líquida é a proporção da população em determinada faixa etária que frequenta a etapa ou nível de ensino adequado a sua faixa etária (IBGE, 2009). Enquanto a taxa bruta de escolarização indica a capacidade de atendimento do sistema, a taxa de frequência bruta revela o grau de atendimento da população em determinada faixa etária, independentemente do nível de ensino; e a taxa de frequência líquida representa o grau de atendimento na faixa etária ideal ${ }^{10}$.

Ao se abordar a taxa de frequência ou escolarização em cada uma das etapas da educação infantil (creche e pré-escola), vale mencionar alguns desafios para sua mensuração. Em razão da história de atendimento da primeira infância no país e de sua conotação para as diferentes classes sociais, são várias as denominações e delimitações de faixa etária nas etapas que compõem a educação infantil, ou seja, muitas vezes não há correspondência entre a divisão das etapas previstas na LDB (creche e pré-escola), com a faixa etária prevista para a mensuração da Meta 1 do PNE (0 a 3 anos e 4 e 5 anos). Além disso, a nomenclatura das políticas públicas e dos equipamentos voltados ao atendimento das crianças de 0 a 3 anos varia conforme 0 município, e nem sempre a matrícula coincide com as faixas etárias previstas na legislação brasileira, ou seja, há um percentual significativo de crianças que não frequenta a etapa que seria adequada à sua idade (ROSEMBERG; ARTES, 2012).

10 Explicação elaborada com base na definição apresentada por Oliveira (2007), utilizandose, porém, a nomenclatura apresentada pelo IBGE. 
O quadro abaixo apresenta as fórmulas de cálculo a depender da taxa de frequência ou de escolarização adotada:

\begin{tabular}{|c|c|}
\hline Taxa de atendimento & Fórmula de cálculo \\
\hline \multirow{2}{*}{$\begin{array}{l}\text { (a) Taxa bruta de } \\
\text { escolarização (1) }\end{array}$} & Pop. matriculada em creche \\
\hline & Total da pop. de 0-3 anos \\
\hline \multirow{2}{*}{$\begin{array}{l}\text { (b) Taxa de } \\
\text { frequência bruta (2) }\end{array}$} & $\begin{array}{c}\text { Número de crianças de 0-3 anos matriculadas em } \\
\text { qualquer nível ou etapa da educação }\end{array}$ \\
\hline & Total da pop. de 0-3 anos \\
\hline \multirow{2}{*}{$\begin{array}{l}\text { (c) Taxa de } \\
\text { frequência líquida (2) }\end{array}$} & Número de crianças de 0-3 anos matriculadas em creche \\
\hline & Total da pop. de 0-3 anos \\
\hline
\end{tabular}

Quadro 2 - Fórmulas de cálculo da taxa de atendimento à creche, ou das crianças de o a 3 anos, segundo o tipo de taxa adotada.

Fonte: (1) IBGE 2014; (2) IBGE 2009.

Elaboração própria.

Para exemplificar as implicações na formulação e acompanhamento das metas previstas nos planos de educação, apresenta-se uma situação ocorrida no município de São Paulo. Em virtude do julgamento de duas Ações Civis Públicas (ACP) ${ }^{11}$ em defesa da garantia do direito à educação infantil, 0 Tribunal de Justiça de São Paulo (TJSP) determinou a criação, pelo município, de 150 mil novas vagas em creches e pré-escolas para crianças de 0 a 5 anos de idade. Determinou também que essa expansão deveria estar prevista em um plano de implementação, a ser monitorado pela Coordenadoria da Infância e da Juventude do TJSP, em articulação com a sociedade civil e os demais componentes do Sistema de Justiça. Antes do julgamento dessas Ações, realizou-se uma inédita audiência pública nesse Tribunal e buscou-se uma solução conciliada entre as partes, que não foi possível, dentre outros motivos, pela divergência que se estabeleceu na análise dos indicadores de atendimento e das metas para sua ampliação ${ }^{12}$.

11 As Ações Civis Públicas foram propostas, entre 2008 e 2010, por organizações que compõem o Movimento Creche para Todos, dentre elas a Ação Educativa, que requeriam a apresentação de um plano público de expansão de vagas, o cumprimento de parâmetros de qualidade e a destinação de recursos orçamentários voltados à educação infantil.

12 Para saber mais sobre os motivos pelos quais não foi possível a conciliação, acesse: 〈http://www.acaoeducativa.org/index.php/educacao/51-acao-na-justica/10004839acoes-judiciais-que-pedem-plano-para-acabar-com-a-fila-de-espera-por-educacaoinfantil-em-sao-paulo-vao-a-julgamento-no-dia-25-de-novembrò. 
Se ambas as partes, a princípio, concordavam com a meta mínima de atendimento de $50 \%$ das crianças de 0 a 3 anos até o final de 2016, já que as ações judiciais requeriam o cumprimento do PNE anterior, havia divergência quanto ao significado quantitativo dessa expansão, tanto em relação ao número de crianças a serem atendidas como no tocante ao número de vagas a serem criadas. Enquanto para a gestão municipal a criação de cerca de 43 mil novas vagas alcançaria a meta pretendida, para os autores das ACP esse número deveria ser ao menos triplicado para se atingir a meta do PNE 20012011. Essa variação pode ser explicada pela diferença no cálculo da taxa de frequência/escolarização: enquanto a gestão municipal utilizou-se da taxa bruta de escolarização (item 'a', Quadro 2), os autores da ação entendiam que a Meta 1.3.1 do PNE 2001-2011 referia-se à taxa de frequência líquida, da população de 0 a 3 anos, já que a população com mais de 3 anos estava contemplada expressamente em meta específica, como vimos. A tabela abaixo apresenta os dados de atendimento das crianças de 0 a 3 anos e do atendimento em creche, no município de São Paulo, calculados segundo os diferentes tipos de taxa de atendimento.

Tabela 2 - Estimativa ${ }^{13}$ por tipo de taxa de atendimento na educação infantil em creche e/ou da população de o a 3 anos, município de São Paulo, 2012

\begin{tabular}{|l|c|c|c|}
\hline & $\begin{array}{c}\text { Número de } \\
\text { crianças } \\
\text { matriculadas } \\
\text { (a) }\end{array}$ & $\begin{array}{c}\text { População } \\
\text { de o a 3 } \\
\text { anos (b) }\end{array}$ & $\begin{array}{c}\text { Proporção } \\
\text { (\%) }\end{array}$ \\
\hline $\begin{array}{l}\text { Taxa bruta de escolarização } \\
\text { (item ‘a', Quadro 2) }\end{array}$ & 262.612 & 610.094 & $43,0 \%$ \\
\hline $\begin{array}{l}\text { Taxa de frequência bruta } \\
\text { (item 'b', Quadro 2) }\end{array}$ & 165.929 & 610.094 & $27,2 \%$ \\
\hline $\begin{array}{l}\text { Taxa de frequência líquida } \\
\text { (item 'c', Quadro 2) }\end{array}$ & 164.975 & 610.094 & $27,0 \%$ \\
\hline
\end{tabular}

Fonte: (a) Microdados Censo Escolar, MEC/Inep, 2012; (b) Projeção Populacional, Seade/IBGE, 2012.

A grande variação nos dados refere-se ao atendimento de crianças que completaram 4 anos e que estão formalmente matriculadas em creche. Recordamos que o estabelecimento da faixa etária entre 0 e 3 anos para 0

13 Esta é uma estimativa, já que as taxas foram calculadas a partir de fontes de dados diferentes (IBGE e MEC/Inep), que apresentam diferentes datas de coleta e corte etário. No entanto, optou-se ainda assim realizar esse cruzamento, já que não se tem disponível um mesmo banco de dados (atualizado anualmente) que apresente dados populacionais e de escolarização por município. 
atendimento em creche foi feito pela LDB/1996. Sabe-se, no entanto, que na educação infantil há grande variação na taxa de frequência em relação a cada idade específica. Por um lado, há um baixo atendimento das crianças menores de 2 anos, enquanto há um número significativo de crianças que completam 4 anos de idade e que permanecem nas creches até o final do ano letivo, para que sejam matriculadas no ano seguinte em turmas de pré-escola.

Outra questão que precisa ser observada nas metas de acesso à educação infantil refere-se à fonte de dados utilizada. Tal como constatado por Rosemberg e Artes (2012), os dados de matrícula em creche do Censo Escolar (MEC/Inep) apresentam-se sempre mais baixos do que os índices de atendimento coletados pelo Censo Demográfico (IBGE). A tabela abaixo ilustra essa situação:

Tabela 3 - Número de crianças de o a 3 anos e de 4 e 5 anos matriculadas ou frequentando creche ou escola, Brasil, 2010

\begin{tabular}{|c|c|c|c|}
\hline Idade & IBGE (1) & Inep (2) & Diferença \\
\hline o a 3 anos & 2.575 .946 & 1.535 .068 & 1.040 .878 \\
\hline 4 e 5 anos & 4.646 .985 & 3.925 .888 & 721.097 \\
\hline
\end{tabular}

Fonte: Adaptado de Rosemberg e Artes (2012). (1) Microdados do Censo Demográfico, 2010 (IBGE, 2012) / (2) Microdados do Censo Escolar, 2010 (MEC/Inep, 2010).

Constata-se que os dados do IBGE sobre a frequência das crianças de 0 a 3 anos apresentam-se mais elevados do que os dados coletados pelo Censo Escolar. Essa variação pode ser explicada por um conjunto de fatores, como as diferenças metodológicas na delimitação da idade da criança e na data de referência das informações, ou ainda em razão das distintas interpretações atribuídas à variável "frequência à creche".

No caso do IBGE, essa variável é compreendida da seguinte forma: “Classificase como frequentando creche a criança que frequenta estabelecimento, juridicamente regulamentado ou não, destinado a dar assistência a crianças nas primeiras idades" (IBGE, Glossário Pnad, p. 24, grifo nosso). Já para o registro no Censo Escolar, é preciso que a frequência da criança ocorra em estabelecimento educacional regulamentado, ou seja, credenciado pelos órgãos competentes e, portanto, capacitado a acessar o sistema de coleta de dados do Ministério da Educação (MEC/Inep). Com base nesse dado, pode-se supor “que a população utilize 'creches ou escolas' que não estão incluídas nos cadastros do INEP por não se caracterizarem formalmente como creches ou escolas" e isso pode ocorrer em virtude de sua baixa qualidade (ROSEMBERG; ARTES, 2012, p. 32). 
Outro aspecto a ser destacado em relação aos indicadores para monitoramento das metas e estratégias de acesso à educação infantil no PNE, sobretudo às creches, refere-se à ausência de dados precisos que permitam a comparação entre a frequência à escola e os dados populacionais. Isso porque apenas o Censo Demográfico (IBGE) permite a desagregação por município, bem como possibilita a comparação entre as características demográficas e educacionais. Ocorre que o Censo Demográfico é coletado de dez em dez anos e, por esse motivo, para utilizá-lo como indicador de monitoramento dessa meta será em geral necessário trabalhar com a projeção dos dados. Quanto mais distante do ano da coleta, no entanto, mais frágeis se tornam as estimativas.

Outra fonte de informação é a Pesquisa Nacional por Amostra de Domicílios (Pnad). Esta apresenta anualmente ${ }^{14}$ dados sobre características demográficas e educacionais da população brasileira, dentre outras, mas não é possível utilizá-la para mensurar a taxa de frequência da população de 0 a 3 anos onde mais interessa, ou seja, nos municípios brasileiros, pois os dados não são desagregáveis nesse nível de detalhamento.

A partir das fontes de informação e dos tipos de indicadores apresentados é possível encontrar uma significativa variação nas taxas de frequência/ escolarização, variação que é exacerbada justamente na faixa etária de 0 a 3 anos, já que seu atendimento ainda se encontra em consolidação no país, onde muitas das instituições popularmente reconhecidas como "creches" não estão formalmente estabelecidas e há uma grande diversidade de arranjos para sua oferta nos municípios brasileiros.

\section{CONCLUSÃO}

0 quadro político-social e institucional relacionado às políticas voltadas à generalização da educação infantil em creches no Brasil exige que, de um lado, prevaleçam decisões tecnicamente sustentáveis e socialmente referendadas na escolha dos indicadores de monitoramento, que devem ser compatíveis com os propósitos amplos do PNE quanto à realização do direito humano à educação, em suas perspectivas subjetiva e objetiva. De outro lado, tal quadro recoloca a necessidade de se aprimorarem as fontes de coleta de dados, de forma a possibilitar o acompanhamento anual do atendimento por faixa etária, em relação aos dados populacionais. Além disso, há a necessidade de se implementar e disseminar os mecanismos de registro da demanda, com o que se completará o quadro necessário para o planejamento e monitoramento,

14 A Pnad só não é realizada no ano de coleta do Censo Demográfico IBGE. 
composto também pelas taxas de frequência bruta e líquida, bem como pela taxa bruta de escolarização.

Deve-se, portanto, estabelecer nacionalmente parâmetros juridicamente adequados, transparentes e socialmente válidos para o cálculo dos indicadores de frequência à creche, já que há grande variação nas taxas de frequência (bruta ou líquida) em relação à taxa bruta de escolarização, conforme demonstrado. Nesse processo, será fundamental o envolvimento dos órgãos técnicos e políticos responsáveis pelo monitoramento do $\mathrm{PNE}^{15}$ e, principalmente, a participação do Fórum Nacional de Educação, das Conferências Nacionais de Educação e de seus congêneres estaduais e municipais.

Certo é que a Meta 1 do PNE, ao determinar literalmente a ampliação “da oferta de educação infantil em creches de forma a atender, no mínimo, 50\% (cinquenta por cento) das crianças de até 3 (três) anos [grifos nossos]" está se referindo à taxa de frequência líquida. Como vimos, a taxa bruta de escolarização é a que apresenta o índice mais elevado, já que inclui as matrículas em creche de crianças com mais de 3 anos de idade, representando, quando muito, a disponibilidade de vagas ofertadas em creche. Ou seja, esse dado não nos permite analisar o cumprimento da meta do PNE, que trata explicitamente do atendimento das crianças por faixa etária em etapas educacionais específicas. Ressalte-se que, do ponto de vista pedagógico, é plenamente defensável a permanência das crianças com mais de 4 anos em creches, como forma de assegurar uma transição adequada à pré-escola ${ }^{16}$. Não podem, no entanto, ser contabilizadas para efeito de cumprimento da Meta 1 do PNE.

Neste momento, as questões relacionadas aos indicadores, instrumentos e direitos regulados no PNE não se aplicam somente ao monitoramento. Dentre as novas normas que deverão ser editadas, já se coloca de imediato, no âmbito de estados, Distrito Federal e municípios, o dever de elaboração de seus correspondentes planos de educação, ou de adequação dos planos já existentes, com ampla participação da comunidade educacional e da sociedade civil (Lei $\mathrm{n}-10$ 13.005/2013, art. 8으).

150 art. 5ํ da Lei no 13.005/2014 atribui o monitoramento contínuo, as avaliações periódicas do PNE e a divulgação dos resultados a um conjunto de órgãos: MEC, Comissões de Educação da Câmara dos Deputados e do Senado, CNE e Fórum Nacional de Educação. Também atribui (art. 5ํㅗ $\$ 2^{\circ}$ ) ao Inep o dever de publicar, a cada 2 (dois) anos, estudos amplos sobre o cumprimento das metas, tendo como referência as fontes de dados já mencionadas e "outras fontes e informações relevantes" que venham a ser produzidas.

16 Mais adequado ainda seria o atendimento de forma integrada da educação infantil, de 0 a 5 anos. 
Evidentemente, uma vez que esses processos de aprovação ou adequação devem se guiar pelas diretrizes da participação democrática, da contextualização e da autonomia regulada dos demais entes federados, não se espera que os planos locais sejam cópias adaptadas do PNE, mas documentos que, partindo de suas diretrizes, metas e estratégias, expressem os desafios e acúmulos específicos que a comunidade escolar e a sociedade civil de cada ente federativo venham a apontar. Esse não deve ser um processo de regulamentação puramente técnico, mas um riquíssimo momento de consolidação da democracia participativa no planejamento e gestão da educação brasileira.

Uma questão central será definir o percentual a ser estabelecido como meta mínima em cada ente federado. Essa meta, adaptada às realidades e exigências locais, será determinada nos processos de identificação da demanda manifesta e de planejamento participativo no âmbito dos municípios e estados. A partir dessa definição, inclusive, será necessário cobrar da União o cumprimento efetivo de sua função supletiva com a educação básica, cujo instrumento essencial é o Custo Aluno-Qualidade (CAQ), na forma como essa obrigação foi amplamente instituída no novo PNE (Estratégias 20.6, 20.7, 20.8 e 20.10). No estabelecimento dos objetivos locais, entretanto, alguns parâmetros deverão ser observados. Primeiro, jurídica e politicamente não se pode admitir retrocesso em relação ao já estabelecido nos planos de educação de municípios e estados, ou seja, se estes reconhecem 50\% como patamar mínimo a ser alcançado em determinado período, esse patamar é o ponto de partida da atualização ou aprovação dos novos planos. Segundo, na mensuração das metas para a próxima década já se devem adotar as estratégias de identificação da demanda manifesta, como determinam várias das estratégias da Meta 1 do novo PNE. Isso quer dizer que, identificada a demanda social efetiva em cada município e respeitados os patamares mínimos estabelecidos, essa demanda deve ser incorporada ao Plano local, sob pena de se configurar omissão no planejamento. Por fim, reiterando o que já foi proposto, a meta de atendimento de 0 a 3 anos deverá ser amplamente discutida e legitimada no processo de planejamento democrático, o que significa que esse processo não pode ser determinado por uma visão meramente tecnicista ou, o que seria um absurdo, por uma simples decomposição aritmética do objetivo nacional mínimo.

Busca-se dar efetividade, antes de tudo, ao direito humano à educação, cuja proteção jurídica é indisponível e inegociável, além de anterior e hierarquicamente superior ao próprio PNE. Este, na verdade, é instrumento de 
realização planejada e participativa daquele direito. Certo é que as interações, por vezes aparentemente conflitivas, entre o direito e o planejamento educacional e entre a participação popular ampliada e os objetivos de articulação e integração nacional, continuarão se manifestando nas agendas de regulamentação do PNE. Esperamos que este trabalho ajude a delimitar esses diferentes aspectos do direito e do planejamento educacional e que, principalmente, seja útil à agenda de formulação, revisão e monitoramento dos planos de educação. 


\section{Access to early childhood education in the new NEP: planning parameters, effectuation and enforceability of this right}

Abstract: This article aims to analyze the content of the first goal of the current National Education Plan (NEP), especially with regard to the fulfilment of the right of access to quality early childhood education. It begins by differentiating the objective goals for expanding access and the right to early childhood education as a required constitutional prerogative in order to demonstrate the place of NEP in Brazilian legal system. Then, the contents of Goal 1 are contextualized in their political and legal aspects, also discussing the strategies that comprise it. We emphasize the need to establish indicators as well as transparent and socially valid parameters for measuring the goal. Finally, challenges for its implementation are presented, concluding with the expectation that the minimum goal of $50 \%$ of access to children up to three years old inscribed in the text of the law should be replaced by the reality of popular pressure with the right of constitutional stature.

Keywords: Early childhood education. National Education Plan. Access to Education. Right to Education. Public Policies. 


\section{REFERÊNCIAS}

AÇÕES judiciais que pedem plano para acabar com a fila de espera por educação infantil em São Paulo vão a julgamento no dia 25 de novembro. Ação na Justiça, 2013. Disponível em: 〈http://www.acaoeducativa.org/index.php/ educacao/51-acao-na-justica/10004839-acoes-judiciais-que-pedem-planopara-acabar-com-a-fila-de-espera-por-educacao-infantil-em-sao-paulo-vaoa-julgamento-no-dia-25-de-novembrò. Acesso em: 20 jul. 2014.

BARROSO, L.R. 0 direito constitucional e a efetividade de suas normas: limites e possibilidades da Constituição brasileira. Rio de Janeiro: Renovar, 2003.

BRASIL. Ministério da Educação. Documento Final da Conae. Brasília, 2010. . Supremo Tribunal Federal. Suspensão de Liminar $n^{0}$ 720/SP. Relator Ministro Presidente, Brasília, DJE no 26, divulgado em 6 fev. 2014. Disponível em 〈http://www.stf.jus.br/portal/processo/verProcessoAndamento. asp?incidente=4465429 . Acesso em: 15 ago. 2014.

CAMPANHA NACIONAL PELO DIREITO À EDUCAÇÃO. Emendas ao PL 8035/2010. Apresentadas em 31/05/2010. Disponível em 〈http://pnepravaler.org.br/wpcontent/uploads/2011/06/Emendas_PNEpraValer_31maio2011.pdf〉. Acesso em 20 ago. 2014.

CANOTILHO, J. J. G. Curso de direito constitucional. Coimbra: Livraria Almedina, 1999.

FUNDAÇÃO SISTEMA ESTADUAL DE ANÁLISE DE DADOS. Informações dos municípios paulistas. Projeção populacional. Disponível em: 〈http://www. seade.gov.br/index.php〉. Acesso em: 23 jul. 2012.

INSTITUTO BRASILEIRO DE GEOGRAFIA E ESTATÍSTICA. Censo Demográfico, 2010.

. Pesquisa Nacional por Amostra de Domicílios (Pnad), 2012.

Glossário Pesquisa Nacional por Amostra de Domicílios (Pnad), 2009. Disponível em: 〈http://www.ibge.gov.br/home/estatistica/populacao/ trabalhoerendimento/glossario_PNAD.pdf〉. Acesso em: 20 nov. 2013.

- Séries históricas e estatísticas. Disponível em: 〈http:// seriesestatisticas.ibge.gov.br/series.aspx?no $=4 \& \mathrm{op}=0 \& \mathrm{vcodigo}=\mathrm{SEE} 16 \& \mathrm{t}=\mathrm{t}$ axa-bruta-escolarizacao-ensino-medio». Acesso em: 20 ago. 2014. 
INSTITUTO NACIONAL DE ESTUDOS E PESQUISAS EDUCACIONAIS ANÍSIO TEIXEIRA. Ministério da Educação. Censo da Educação Básica, 2010 e 2012.

OLIVEIRA, R. P. Da universalização do ensino fundamental ao desafio da qualidade. Educação e Sociedade, Campinas, v. 28, n. 100 - Especial, p. 661690, out. 2007.

RIZZI, E.; XIMENES, S. B. Litígio estratégico para a mudança do padrão decisório em direitos sociais: ações coletivas sobre educação infantil em São Paulo. In: ENCONTRO DA ANDHEP, 8., 2014, São Paulo. Anais... São Paulo: ANDHEP, 2014, p. 2471-2992.

ROSEMBERG, F.; ARTES, A. O rural e o urbano na oferta de educação para crianças de até 6 anos. In: BARBOSA, M. C. S. et al. (Org.) Oferta e demanda de educação infantil no campo. Porto Alegre: Evangraf, 2012.

XIMENES, S. B. Padrão de qualidade do ensino: desafios institucionais e bases para a construção de uma teoria jurídica. 2014. 424f. Tese [Doutorado em Direito do Estado] - Universidade de São Paulo, São Paulo, 2014.

RECEBIDO: Setembro de 2014.

APROVADO: Outubro de 2014. 